\title{
Spheroid-based 3D Cell Cultures Enable Personalized Therapy Testing and Drug Discovery in Head and Neck Cancer
}

\author{
JAN HAGEMANN ${ }^{1 *}$, CHRISTIAN JACOBI ${ }^{2 *}$, MORITZ HAHN ${ }^{2}$, VANESSA SCHMID ${ }^{2}$, CHRISTIAN WELZ 2,3 , \\ SABINA SCHWENK-ZIEGER ${ }^{2}$, ROLAND STAUBER ${ }^{1}$, PHILIPP BAUMEISTER $^{2}$ and SVEN BECKER ${ }^{1,2}$ \\ ${ }^{1}$ Department of Otorhinolaryngology, Head and Neck Surgery, \\ University Medical Center of Johannes-Gutenberg University, Mainz, Germany; \\ ${ }^{2}$ Department of Otorhinolaryngology, Head and Neck Surgery, \\ Ludwig-Maximilian-University Medical Center, Munich, Germany; \\ ${ }^{3}$ Department of Otorhinolaryngology, Head and Neck Surgery, \\ University of Göttingen Medical Center, Göttingen, Germany
}

\begin{abstract}
Background/Aim: Chemo-radiation currently serves as first-line therapy of advanced and recurrent head and neck cancer, while new chemotherapy regimens are emerging. However, response rates to any treatment are difficult to predict and underlie broad variation. This study shows the development of a standardized, high-throughput in vitro assay to assess patients' individual response to therapy regimens as a future tool for personalized tumor therapy. Materials and Methods: Viability and proliferation analyses after chemo +/- radiation treatment of single spheroids (low adhesion plates/Hanging Drop (HD)) were generated from head and neck squamous cell carcinoma (HNSCC) cell lines and primary human cells from fresh tumor specimens. Results: All cell lines showed reliable growth in all cell culture methods. The spheroids showed significant delay of growth and/or necrosis compared to control groups when exposed to current standard chemotherapeutic regimens. Single $3 D$ spheroids ready for therapy susceptibility testing could be generated from actual tumor specimens after enzymatic and mechanical separation. Conclusion: In its current form, this single spheroid-based in vitro assay was able to test individual therapy susceptibility to current standard therapy regimens or, potentially, for testing
\end{abstract}

This article is freely accessible online.

*These Authors contributed equally to this study.

Correspondence to: Sven Becker, Department of Otorhinolaryngology, Head and Neck Surgery, University Medical Center of Johannes Gutenberg University, Langenbeckstr. 1,55131 Mainz, Germany. Tel: +49 6131177361, Fax: +49 6131176637, e-mail: sven.becker@unimedizinmainz.de

Key Words: Head and neck cancer, personalized medicine, 3D cell culture, HNSCC, tumor therapy. new targeted drugs in HNSCC treatment. With recent discoveries regarding tumor heterogeneity and individual mutation status, a reliable assay is a prerequisite for personalized therapy in head and neck cancer.

Head and neck squamous cell carcinoma (HNSCC) is the sixth most common cancer worldwide and predominantly caused by excessive nicotine and alcohol consumption $(1,2)$. A smaller, however, emerging number of cancers are caused by permanent mucosal infection with high-risk types of human papillomavirus (HPV) (3). There have been few advances in improving overall and disease-free survival rates in the past decades for advanced, recurrent and metastatic disease (4-6). Surgical and conservative options are often limited in these cases, as certain cancers show significant resistance to chemo- and radiotherapy (7-11). While targeted therapy has been successful in other oncologic entities, there has been only one approval in HNSCC for cetuximab, a therapeutic antibody against epidermal growth factorreceptor (EGFR) $(4,5)$. Other targeted therapy drugs like checkpoint inhibitors have only recently made transition from trial to approval $(12,13)$.

Mechanisms of resistance to radio- and chemotherapy are insufficiently understood and response rates are more or less unpredictable, making decisions for appropriate treatment modalities difficult for doctors and patients. Thus, in HNSCC, there is rather a choice of treatments than a treatment of choice. Moreover, ineffective radio- and chemotherapy comes at a high cost of significant patient morbidity without significant tumor regression. There have been implications for differences in response rates between HPV-negative and HPVassociated head and neck cancers; however, these indicators have not yet led to a change in therapy guidelines (14-17). Recent ground-breaking studies have identified a large variety of inter-individual and intra-individual heterogeneity as a key 
reason for treatment resistance (18-21). Several cancer cell clones with unique sets of driver mutations can be found within a single tumor (22). Nonetheless, detailed analyses of genetic alterations occurring in an individual cancer are costand time-expensive. Moreover, knowledge of genotype does not necessarily allow for reliable prediction of phenotype and its treatment response.

Current experimental approaches for therapy studies make use of in vivo and in vitro techniques, with animal models being the most challenging and cost-intensive approaches. None of the techniques copies the variability in terms of genetic alterations and cell heterogeneity in the same way as the real cancer does as they often comprise the use of heavily altered and aged cell lines with few reliable matching characteristics to actual human tumor cells. To address this problem, we were recently able to generate a new cell line referred to as " $\mathrm{PiCa}$ " derived from fresh human cancer biopsies without enzymatic degradation and with tumor-forming capacity in animal models (23). With limited passages and characterization confirming conserved cellular markers on the cell surface, on the road to future trials with primary human cells, this cell line was our main focus in the development of the following model.

To date, several approaches of 3D tumor models like spheroids and embedded matrix cultures have been followed, usually in the context of identifying subsets of tumor stem cells and their migratory capacities (24-28). It has been shown that cells in three-dimensional (3D) cultures react differently and more in vivo-like to administration of cancer drugs than in monolayers (29-33). We intended to generate a three-dimensional spheroid-based model to test individual tumor therapy susceptibility, with the long-term goal of using cells from freshly taken tumor biopsies that would allow us to determine the ideal therapy regimen and identify patientspecific mutation status and therapy targets (Figure 1A). Here, we report the process of generating such a standardized model to its current form.

\section{Materials and Methods}

Cell lines and cell culture. Four different cell lines and human primary cancer cells were used. FaDu and Cal27 (both human, from hypopharyngeal and tongue cancer, respectively) were obtained from ATCC (Manassas, VA, USA). The UPCI-SCC-154 cell line from oropharyngeal HPV-associated cancer was obtained by U. Schoetz (Department of Radiation Oncology, Munich, Germany). The intermediate cell line $\mathrm{PiCa}$ originated from our associated workgroup at Großhadern campus (23). Cells were cultured in Dulbecco's modified Eagle's medium (DMEM; Biochrom, Berlin, Germany) supplemented with $10 \%$ fetal bovine serum (Gibco Life Technologies, Paisley, UK), 1\% penicillin/streptomycin (Biochrom), $1 \%$ sodium pyruvate (Biochrom), $1 \%$ non-essential amino acids (Biochrom) and 1\% L-Glutamine (Gibco Life Technologies). Cell splitting was performed according to standard cell culture protocols. Primary human tumor cells were harvested from tumor biopsies incubated with Liberase (Roche Life Sciences, Basel, Switzerland) and sieved before cultivating them in FCS-free medium to suppress overwhelming fibrocyte growth. A further characterization of the cells was performed, though not subject of this particular study.

Spheroid cell culture. Different methods were used throughout the process of establishing the most promising spheroid cell culture generation. For the generation of Hanging Drops (HDs), a cell suspension of 1,000 $(\mathrm{FaDu})$ or 2,000 cells ( $\mathrm{Cal} 27)$ was used in the GravityPLUS $^{\mathrm{TM}}$ 3D Culture and Assay Platform (InSphero, Schlieren, Switzerland). The platform was then incubated as described previously (34). Depending on cell line, $3(\mathrm{FaDu})$ to 5 (Cal27) days turned out to yield the best results in terms of morphology. The harvesting process is induced by transferring the GravityPLUS ${ }^{\text {тм }} 3 \mathrm{D}$ Culture and Assay Platform on a GravityTRAP ${ }^{\mathrm{TM}}$ plate. Subsequently, the spheroids are harvested by pipetting $70 \mu$ of DMEM into the wells of the GravityPLUS ${ }^{\mathrm{TM}}$ plate that drives the spheroids to drop into the wells of the GravityTRAP ${ }^{\mathrm{TM}}$ plate, allowing long-term culture and imaging. Ultra-low attachment (ULA) culture plates were used for the tested cell lines (96-well spheroid microplates with ULA surface; Corning, Corning, NY, USA) at a cell suspension containing 1,000 PiCa, 1,000 FaDu, 2,000 Cal27 and 2,000-5,000 cells/ml UPCI SCC154 cells, respectively, depending on the trial.

Multimodal therapy testing. For evaluating effects of chemotherapeutic and radiation treatment on cell lines in 3D models, two treatment regimes were created. The first approach comprised radiation treatment of 2 Gy one day after harvesting and an additional chemotherapeutic treatment with cisplatin $(2.5 / 5 / 10 \mu \mathrm{M})$ for $24 \mathrm{~h}$. In the second approach, chemotherapeutics were given alone without simultaneous radiation. After 24 hours, the medium was aspirated and replaced through a 50/50 mixture of DMEM and airway epithelial cell growth medium (Promocell, Heidelberg, Germany) supplemented with $0.2 \%$ amphotericin B (Biochrom), 5\% gentamicin (Promocell) and the airway epithelial cell growth medium supplement mix (Promocell). The spheroids were then cultured for 15 days under the same conditions as stated before, with medium exchange on every second day. All experiments were performed in, at least, 5 independent replicates. Cells were starved in FCS-free medium for $24 \mathrm{~h}$ before the beginning of any experimental incubation.

Planimetric assessment and proliferation testing. The development of the spheroids was observed and documented every day of the culture period via light microscopy and photography. Pictures were analyzed with Image J (public software distributed by the National Institutes of Health) by measuring area and diameter of the spheroids. To assess proliferation and, therefore, viability at the end of the experiment, a standard commercially available colorimetric WST-8 test (PromoCell, Heidelberg, Germany) was performed and analyzed by ELISA.

Statistical analysis. Statistical analyses were performed with SPSS (IBM, Armonk, NY, USA). A $p$-value $<0.05$ (two-tailed) was considered statistically significant.

\section{Results}

Comparing spheroids from Hanging Drop (HD) and ultralow attachment (ULA) assays. Although several spheroid studies have been performed by numerous working groups in the context of tumor cell lines, limited information was 

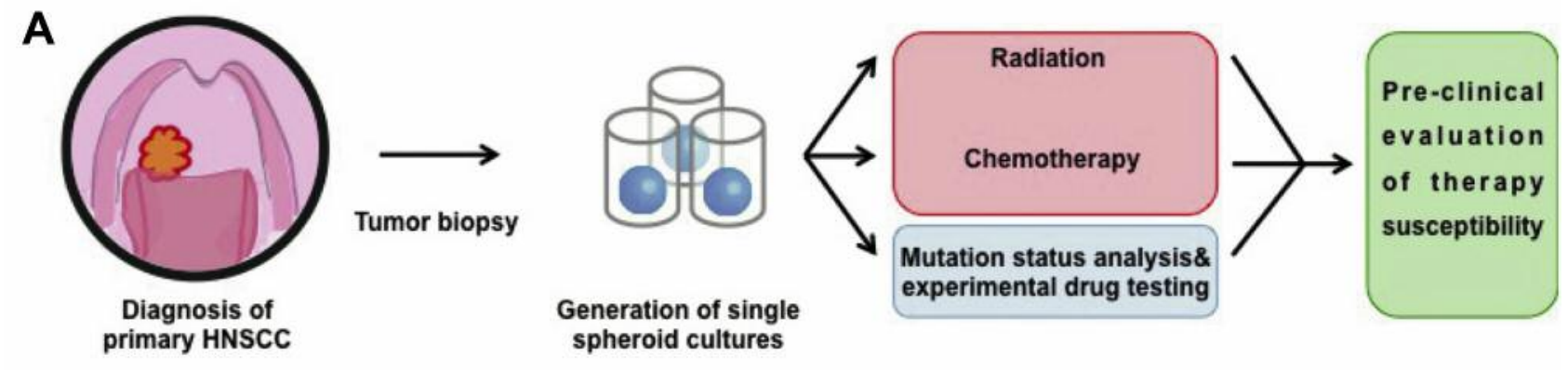

B

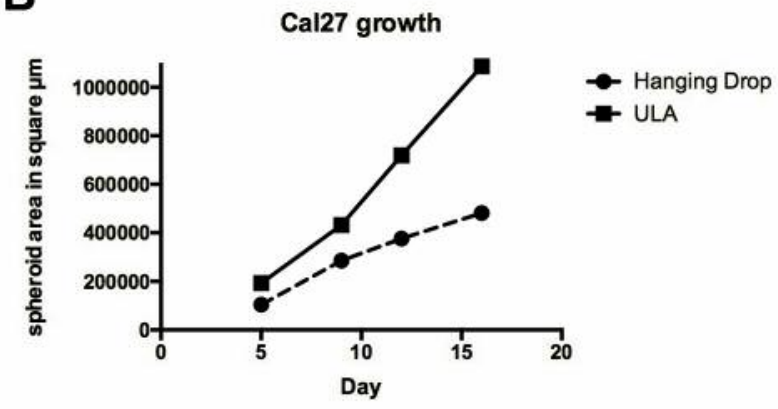

FaDu growth

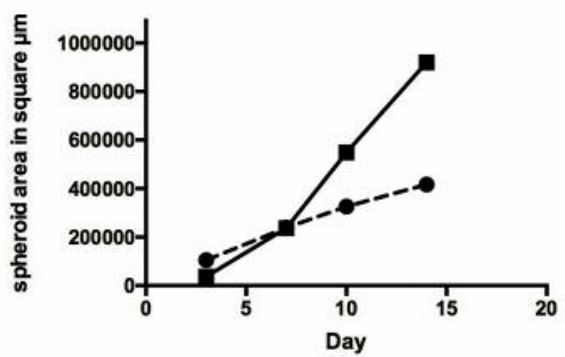

PiCa growth

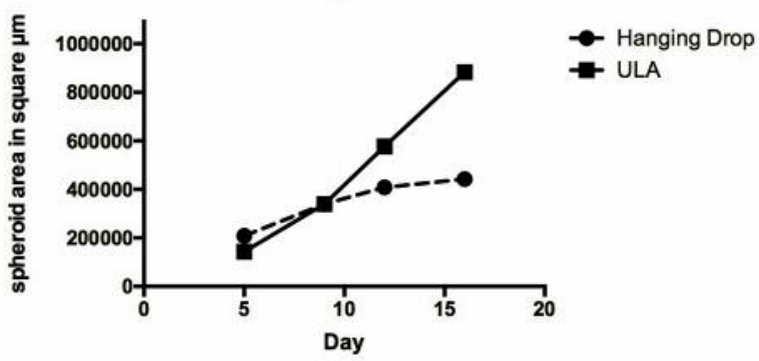

C
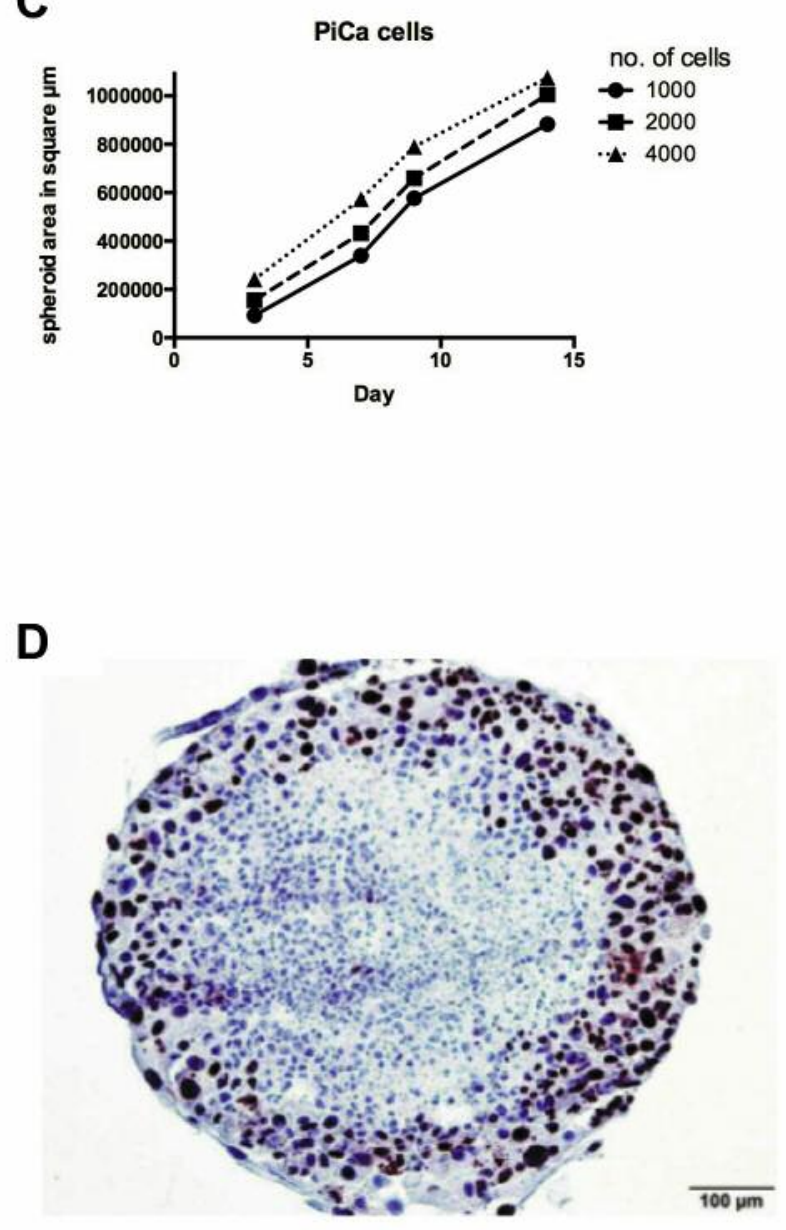

Figure 1. General concept of pre-therapy susceptibility testing and comparison of methods. A: Scheme of theoretical preclinical therapy and mutation testing. B: Growth rates of head and neck squamous cell carcinoma (HNSCC) cell lines in both spheroid cell culture models. Cal27, FaDu and PiCa cells were seeded into either Hanging Drop (HD) arrays or ultra-low attachment (ULA) plates. While PiCa and FaDu spheroids required 1,000 cells per well, a number of 2,000 Cal27 cells was necessary to obtain comparable spheroid formation after 14 days. ULA-generated spheroids were significantly larger compared to HD spheroids. C: Comparison of growth speed with increased number of cells (PiCa cells on ULA). The linear pattern remains unchanged. D: Ki67 immunochemistry staining of a spheroid slice. The periphery of the culture shows much higher proliferation rates than central cells, mimicking nutrient distribution in solid mucosal tumors that often show necrotic cores (PiCa cells on ULA plates). 


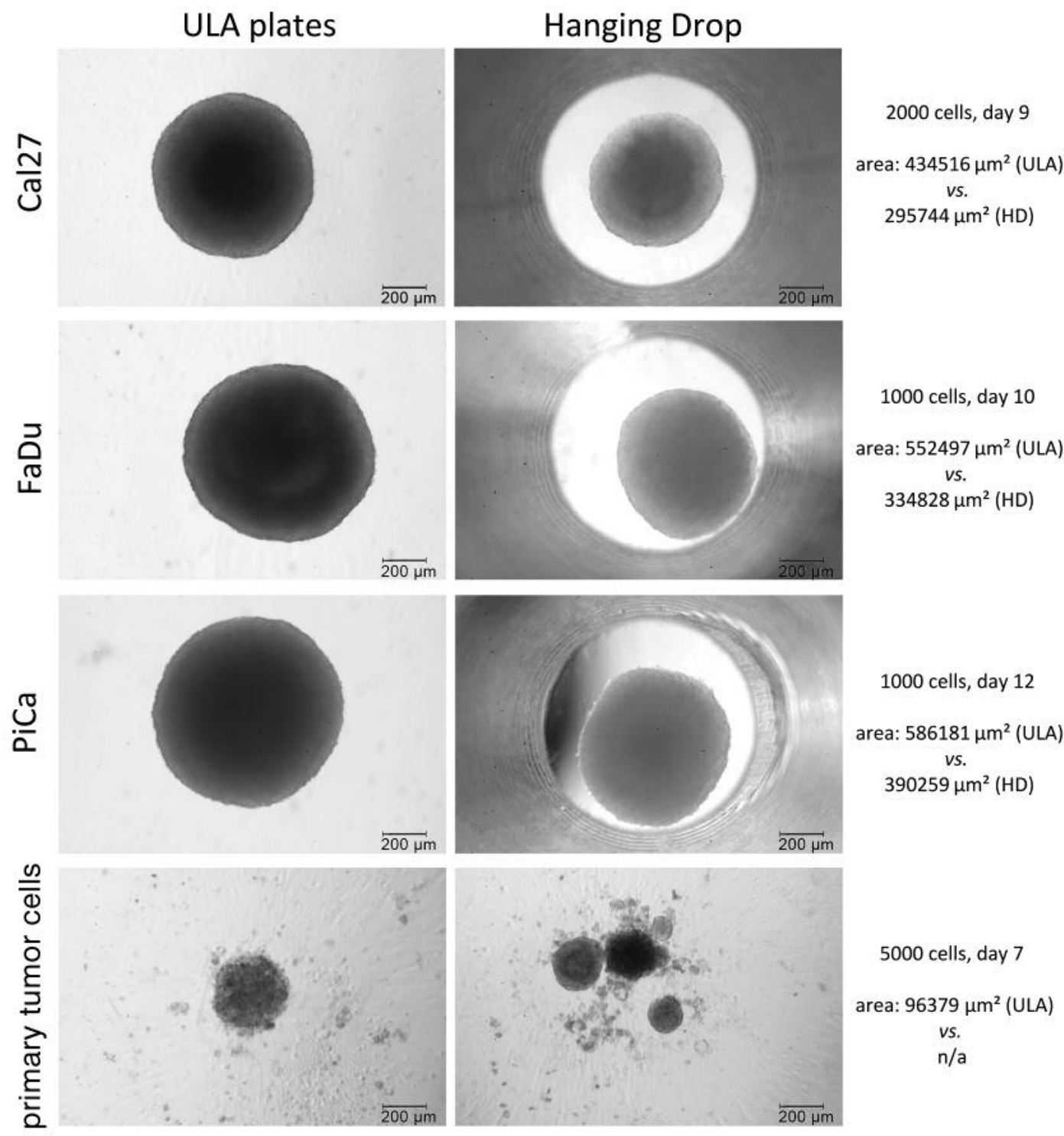

Figure 2. Microscopy of spheroids from different cell lines and primary tumor cells. All cell lines could generate reliable spheroids; differences in size and time of read-out are according to Figure 1. In preliminary experiments, primary cells did not form reproducible spheroids in Hanging Drop (HD) but ultra-low attachment (ULA) plates (bottom left). Further studies are to be undertaken to evaluate spheroid growth characteristics from primary cells.

available regarding how cells from squamous cell carcinoma from the head and neck would perform in such assays and, also, which assay would be best suitable for potential therapy studies. We have been working with, namely, two common spheroid cell culture assays in our group, the HD assay and an assay based on ULA plates.

The HD model belongs to the methods of liquid-based suspension cultures that maintain culture cells in suspension to ease self-assembly of the tumor cells into spheroids (33). Thus, the spheroids arise due to gravity-induced aggregation of the cells without coating the surface of the plate, preventing interactions and effects of cells with the substratum $(29,31)$. ULA plates consist of non-adherent polystyrene surfaces with opaque sides and a round-shaped well bottom that lead to reproducible homogenous formation of single multicellular tumor spheroids (MCTS) per well without any fixation on the culture plate $(35,36)$. After seeding variable cell numbers, a spheroid remains within the same well and does not need to be transferred before further treatment. Due to the bigger diameter of the well, the spheroids obtain bigger sizes compared to the HD model. Depending on the cell line, a stable, round and uniform 


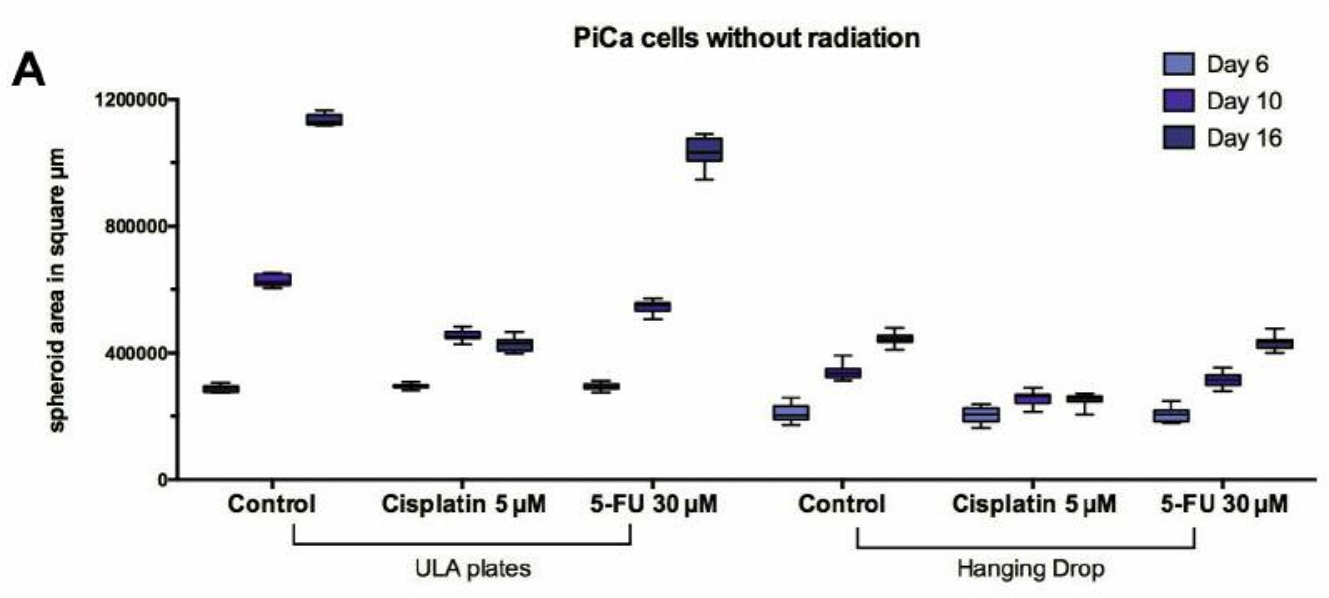

B

PiCa cells with 1x 2Gy radiation

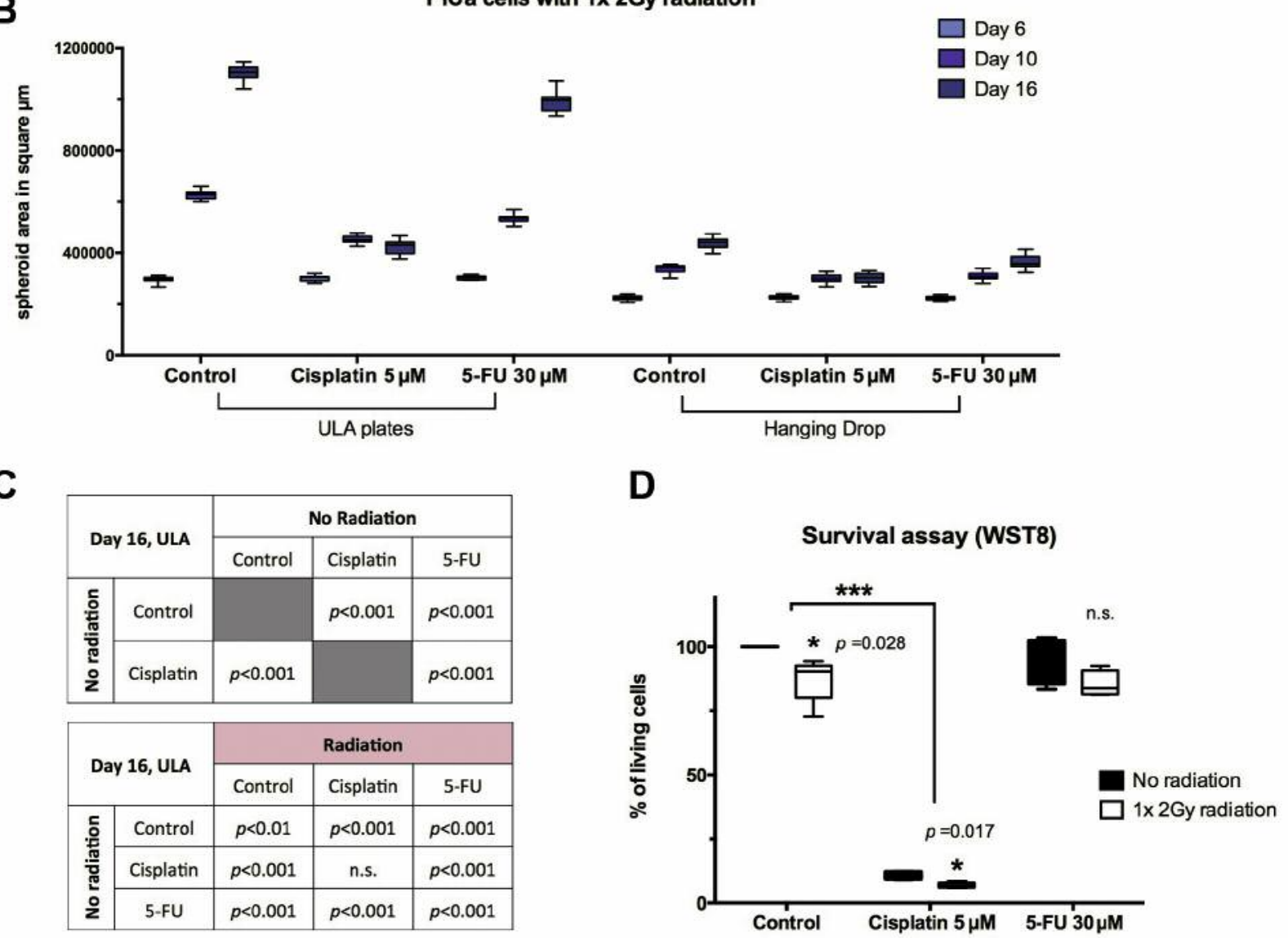

Figure 3. Therapy studies. A: PiCa cells were cultivated to generate spheroids ( $n=12$ per group) in ultra-low attachment (ULA) plates and Hanging Drop (HD). Cells were stimulated according to the protocol (see Materials and Methods) with either $\mathrm{H}_{2} \mathrm{O}$ as control, cisplatin at $5 \mu \mathrm{M}$ or 5-fluorouracil (5-FU) at $30 \mu \mathrm{M}$. Sizes of the spheroids were determined at day 6, 10 and 16 according to standard protocols. Cisplatin and 5-FU treatment led to a significant decrease in size (p-values are given at left bottom under section C). HD spheroids were significantly smaller than ULA spheroids. Due to handling difficulties and subsequent loss of cells, this technique was not suitable for manual testing in high numbers. B: Identical experimental design as in A (n=12), but with additional radiation of $2 G y$. According to the p-values given in C, previous radiation with 2 Gy led to a significant decrease in spheroid size in the control group, imitating radiation therapy and showing radiation sensitivity of PiCa cells. Radiation in combination with cisplatin treatment did not lead to a further significant decrease in size of the spheroid ( $p>0.05)$. C: calculated $p$-values from 2-way ANOVA analysis from experiments A and B. D: WST8 assay performed on day 16 as an alternative for planimetric analysis of the spheroids. WST8 analyses were able to detect a significant decrease in living cells after chemo-radiation (2Gy radiation and cispatin) compared to cisplatin only ( $p=0.017)$, hence showing the advantage of combining both planimetric analysis and WST8 colorimetric assay at the time of assay read-out. 
Table I. Synopsis of Hanging Drop (HD) and ultra-low attachment (ULA) model's characteristics $(28,33)$.

\begin{tabular}{lll}
\hline Spheroid model & Advantage & Limitations \\
\hline Hanging Drop method & $\begin{array}{l}\text { Uniform morphology and size of spheroids } \\
\text { Single spheroid per drop }\end{array}$ & $\begin{array}{l}\text { Difficult handling, risk of dissolving spheroids } \\
\text { Not compatible with most plate readers }\end{array}$ \\
& $\begin{array}{l}\text { High throughput possible } \\
\text { Automation possible (robotics) } \\
\text { ELA plates }\end{array}$ & $\begin{array}{l}\text { Morphology and size of spheroids may vary } \\
\text { High throughput possible } \\
\end{array}$ \\
& Automation possible (robotics and plate readers) & $\begin{array}{c}\text { Slight tendency towards multiple spheroids } \\
\text { per well depending on cell type }\end{array}$ \\
\hline
\end{tabular}

morphology of the spheroids allows further high-throughput screening $(35,37)$. Table I shows a synopsis of both techniques' characteristics.

We have been working with several established cell lines throughout the process of finding a feasible protocol for the pre-clinical therapy testing. To obtain comparable spheroids with adequate morphology and size, individual numbers of cells had to be seeded for each cell line. We further compared the individual growth rates of $\mathrm{PiCa}, \mathrm{FaDu}$ and $\mathrm{Ca} 27$ spheroids for a period of 14 and 16 days, respectively and for each model. The growth rates were nearly linear in both models, with the average growth rate, however, being approximately twice as high in ULA plates compared to HD (Figure 1B). A change in cell number at the beginning of the experiment did not change the linear growth pattern but led simply to an increase in surface area (Figure 1C). Both models revealed reproducible spheroids with stable cell-cell adherence leading to dense and round clusters. After 7 days of cultivation, light microscopy showed spheroid morphology with a dense core and brightened outer cell layer (Figure 2). To check for a more distinct spheroid anatomy and obtain more information about the growth pattern and cell viability, we performed immunochemistry on spheroids with the proliferation marker Ki-67. The experiment revealed differences between the fast proliferating tumor rim of about $500 \mu \mathrm{m}$ thickness and the spheroid core with only slow proliferating cells as shown for other small, not vascularized solid tumors (Figure 1D). This is most likely caused by a gradient of nutrients and oxygen supplied by the cell culture media causing a decrease from the periphery to the center of the tumor. Overall, spheroid formation with primary tumor cells previously obtained from biopsies was more reliable and reproducible in ULA plates than in HD, which supported our decision to proceed preferably with ULA plates for future trials.

Treatment studies with first-line radio-chemotherapy. For patients unsuitable for surgery due to excessive local tumor growth and metastatic spread, the current first-line therapy recommendations enclose fractionated radiation, usually at single doses of $2 \mathrm{~Gy} / \mathrm{day}$ and simultaneous chemotherapy with at least one platinum-derived drug. Similar treatment regimens are also given for adjuvant therapy after successful surgical removal of the tumor. Before being able to establish the assay for therapy susceptibility testing, we had to check whether our analysis methods were able to detect decreases in spheroid size after incubation with chemotherapeutic drugs or exposure to radiation. Figure 3 shows the results of our therapy studies with PiCa cells; testing with the other three cells lines revealed similar results (data not shown). Incubation of cells with cisplatin or 5-fluorouracil (5-FU) led to a significant decrease of spheroid growth over time in both models (Figure 3A). Radiation of 2 Gy also significantly reduced spheroid growth (Figure 3C). In planimetric analysis of the spheroid size, combination of both radiation and cisplatin treatment did not show a significant decrease in spheroid size; however, the WST8 analysis, to assess the proportion of viable cells at day 16 , showed a significant added negative impact of radiation + cisplatin compared to cisplatin alone (Figure 3D).

\section{Discussion}

We could successfully implement a standardized method to, first, generate multicellular spheroids from different HNSCC cell lines and, subsequently, establish a reliable protocol to measure spheroid size and viability. The experiments performed on this issue were also conducted preliminarily with primary tumor cells originating from fresh tumor biopsies confirming feasibility. This is the first step towards an assay that can be used to assess (i) tumor heterogeneity using cells originating from different parts of tumor or primary $v s$. metastatic cells and (ii) individual susceptibility to common first- or second-line therapy protocols (chemo-reagents, radiation) and experimental drugs. Our experiments confirmed current data regarding superiority of cisplatin with radiation versus radiation alone $(p=0.017)$ on cell lines; however, a multimodal assay readout with both planimetric analysis and survival assay seems mandatory to increase the assay's sensitivity for reliable detection of small variations. 
In general, there is an urgent need to re-think and reevaluate existing and previous techniques used to measure therapy response in an experimental setting. Many of the preliminary studies were performed with cancer cell lines originating from decades earlier, either in in vitro or in animal models. Therefore, several genetic alterations during the numerous passages in vitro, compared to the original cell line, are assumed causing different behavior when exposed to radiation and/or chemotherapy. Cell lines that are able to grow in vitro differ genetically from the primary cancer cell population. Selective pressure in vitro may predominantly maintain their increased growth stimulation in terms of autocrine secretion of growth factors. Hence, results of therapy susceptibility testing in non-primary tumor cells indicate rather an overall, i.e. qualitative, effect of a treatment regime but there is no evidence of the same effect applied in patients (38, 39). The reality of treating HNSCC has been more difficult than experimental studies suggested earlier with high numbers of therapy resistance mechanisms and, virtually, no way of predicting effectiveness. To our knowledge, there is no other experimental or clinical in vitro assay that comprises of primary tumor cells. We confirmed feasibility with primary cells in regards to reliable spheroid formation in small preliminary numbers; however, to date, further and larger experiments have to be performed before being able to establish the method as a clinical assay, which is the goal of these efforts.

With our new intermediate cell line PiCa from our group, we were able to conduct treatment experiments at a larger scale and confirmed current therapy expectations (23). While this might seem like a circumstantial fact, it supports our theory that $\mathrm{PiCa}$ cells reflect actual human tumor behavior better than other, more aged and passaged cell lines that underwent numerous passages. Cells that may undergo nonphysiological selection due to long-term in vitro conditions might bias chemo-radiation sensitivity. In this respect, $\mathrm{FaDu}$ cells, derived from a tumor biopsy taken in 1968, may not be suitable for the prediction of treatment response of individual carcinomas In general, none of the available cancer model systems (2D cell cultures, animal models) could come out on top in regards of drug discovery as, even in animal studies, some of formerly promising preclinical drugs failed to be reproducible in patient treatment (40). Many animal models include the use of immune incompetent mice; however, in the light of recent drug discoveries; we know that the immune system is a key player influencing therapy mechanisms and nowadays a target of therapy itself. Therefore, such a notion should not be generally excluded in therapy assays (41).

Current emerging approaches towards personalized therapy in HNSCC patients enclose tumor cell-DNA sequencing and histopathological evaluation of certain markers. Evaluation of cell surface markers is not new in the context of HNSCC. While earlier testing for EGFR density on tumor cell surface was not useful to predict the effectiveness of cetuximab, there seems to be a certain correlation between the extent of presentation of PD1 ligand on tumor cells and the effectiveness of now emerging checkpoint inhibitors in head and neck cancer (42-44). DNA sequencing approaches are aiming towards identification of future therapy targets, i.e. for monoclonal antibodies, but HNSCC remains difficult to generalize between individual patients due to a high rate of mutation quantity and variability. These instruments are also easy to be integrated in our 3D spheroid approach, as single spheroids could be analyzed as described above from their ULA plate, i.e. to test for medication prerequisites right away after failure of current standard therapy regimens. While delivering a maximum of information, new emerging methods like sequencing and proteomics remain a financial challenge and, therefore, hard to implement into clinical routine. With our assay up-front, they could be used specifically in cases showing resistance to other common treatment regimens.

A main precondition for high-throughput screening is the reproducibility of uniform spheroids as size and heterogeneity may influence the validity of end-point assays (45). We showed that spheroids grow in a linear pattern with higher proliferation rates in ULA plates resulting in significant increased spheroid sizes compared to HD. This finding was independent of the initial amount of seeded cells. Light microscopy revealed regular spheroids of all cell lines with dense cores and brightened outer cell layers on day 7 of cultivation. This contrasts the theory of a typically biphasic growth behavior as a result of the spheroid morphology of a rising necrotic core, a quiescent cell layer with cell-cycle arrest and a thin outer proliferative cell layer $(30,31$, 46). Little is known about the assessment of the individual ideal spheroid size and time point to start treatment and/or read-out slight differences with high sensitivity. In general, on the one hand, cell incubation should not be initiated unless spheroid morphology is present; on the other hand, the effect of treatment seems to shrink when spheroids gain excessively extended sizes. From our experience, we regard the 16-day culturing time as maximum until spheroids show tendencies towards growth stagnation, dissociation and infection. In this trial, 1,000-2,000 cells proved to be sensitive to detect differences after treatment. It was shown that multicellular tumor spheroids reach sizes of 1 to $3 \mathrm{~mm}$ in diameter, depending on the cell line and the 3D model $(29,47)$. Typical spheroid architecture, consisting of a an inner layer of quiescent cells and an outer layer of proliferating cells, respectively, was detected in MCTS lager than $500 \mu \mathrm{m}$ in diameter, an indication of nutrition, oxygen and, thus, proliferation gradients responsible for cell heterogeneity $(29,32,47)$. These limited diffusion gradients of oxygen, nutrients, metabolic waste products and soluble factors, such as cytokines and growth factors, were shown to be similar to micro-metastases and avascular tumors measuring $0.5-1.0 \mathrm{~mm}^{3}(37,45,48)$. 
Why do 3D tumor cell cultures make sense in preclinical use? Several studies have shown that 2D and 3D cultures simply react differently to anticancer drugs and radiation. Not all studies are comparable, as they work with different assays and cell types, but could generate significant results when comparing 2 and 3D culture assays. The variability of drug susceptibility is usually explained by different "microenvironments" and gene expression profiles, apart from nutrient and oxygen gradients and diffusion capacity of the drug $(29,49,50)$. Pickl et al. recently pointed out a good example for the role of such microenvironments in which trastuzumab was tested in 2D and 3D environments of breast cancer cells (51). Cells in 3D spheroids where much more vulnerable to the antibody as they depended significantly more on their physiological human epidermal growth factor receptor 2 (HER2) signaling in the spheroid formation, the target of the antibody (45). Therefore, predicting clinical response of new agents tested in 2D cellular assays is limited (32). Although 3D cell culture models are commonly seen to be superior to monolayer cultures as a more reliable drug screening tool, there are only a few studies that deal with spheroids in head and neck cancers $(27,33,52-54)$.

In this work, we discuss spheroid models that may close the gap between the basic and less physiological monolayer models, on one hand and, even more sophisticated, likely unpractical for routine 3D models harboring co-cultures like stromal cells and immune cells, on the other hand (29). Among a wide range of different $3 \mathrm{D}$ models with variable complexity, it seems important to focus on scaffold-free MCTS like the HD and the ULA method, respectively, as they represent an auspicious tradeoff between easy handling for high-throughput screening and enhanced reflection of tumor physiology $(32,45)$. One of the major limitations that 2D and 3D cultures have in common is the lack of examining migration and invasion of the malignant cells. As spheroids consist of a distinct construction (hypoxic core enriched with a quiescent viable central zone with tendency to necrosis, as well as the outer proliferating zone) the rates of proliferation of several tumor cell lines might be reduced compared to its behavior in a 2D model (45). The underlying mechanisms include different oxygen/nutrient/growth factor gradients, stromal cell and extracellular matrix influence (30, 55-58). However, 3D models represent the most promising tumor model before moving to expensive animal models that remain the most predicting models for preclinical drug testing (59).

Drug resistance has been brought-up repeatedly in the context of spheroid cell culture models. Several treatments have been found to be less effective in 3D pathophysiological environment indicating either different rates of drug resistance or, actually, a more realistic effectiveness compared to clinical use $(39,50)$. This might be due to drug concentration gradient from the outer cell layers to the inner core, mimicking a more physiological drug delivery within the tumor due to reduced permeability $(33,60,61)$. Furthermore, in 3D models, cells seem to express distinct genes usually associated with drug resistance that were also found in in vivo animal studies (58). Factors, such as alteration of chromatin structure, apoptosis inhibition, cell cycle and permeability, make the MCTS a more reliable and predictable drug testing in vitro model compared to 2D monolayer models (29, 37, 62-64). Radiation resistance has also been linked to spheroid models in the past. Kadletz et al. could not detect any radiationrelated cytotoxicity for a variation of dosages in different HNSCC cell lines (52). However, sensitivity and resistance to irradiation is mainly influenced by effectiveness of DNA repair, apoptosis, oxygen supply and cell-cell contacts, features that, in spheroid cell culture, are similar to tumors in vivo $(29,65,66)$. In conclusion, it is plausible that the so-called chemo- and radiation resistance, in the context of spheroid cell culture, is actually the result of more in vivolike cell functionality. Actual drug effectiveness and the complex mechanisms behind drug resistance could be understood in spheroid cell culture models much better even, possibly, in a preclinical setting.

\section{Acknowledgements}

The Authors thank Sabina Schwenk-Zieger, Mortiz Hahn for the conduction of the experiments and all co-authors for their critical comments and review along the project. This project was funded by a grant of the Universität München.

\section{References}

1 Hunter KD, Parkinson EK and Harrison PR: Profiling early head and neck cancer. Nat Rev Cancer 5: 127-135, 2005.

2 Jerjes W, Upile T, Radhi H, Petrie A, Abiola J, Adams A, Kafas P, Callear J, Carbiner R, Rajaram K and Hopper C: The effect of tobacco and alcohol and their reduction/cessation on mortality in oral cancer patients: short communication. Head Neck Oncol 4: 6, 2012.

3 Ang KK, Harris J, Wheeler R, Weber R, Rosenthal DI, NguyenTan PF, Westra WH, Chung CH, Jordan RC, Lu C, Kim H, Axelrod R, Silverman CC, Redmond KP and Gillison ML: Human papillomavirus and survival of patients with oropharyngeal cancer. N Engl J Med 363: 24-35, 2010.

4 Bonner JA, Harari PM, Giralt J, Azarnia N, Shin DM, Cohen RB, Jones CU, Sur R, Raben D, Jassem J, Ove R, Kies MS, Baselga J, Youssoufian H, Amellal N, Rowinsky EK and Ang KK: Radiotherapy plus cetuximab for squamous-cell carcinoma of the head and neck. N Engl J Med 354: 567-578, 2006.

5 Vermorken JB, Mesia R, Rivera F, Remenar E, Kawecki A, Rottey S, Erfan J, Zabolotnyy D, Kienzer HR, Cupissol D, Peyrade F, Benasso M, Vynnychenko I, De Raucourt D, Bokemeyer C, Schueler A, Amellal N and Hitt R: Platinumbased chemotherapy plus cetuximab in head and neck cancer. $\mathrm{N}$ Engl J Med 359: 1116-1127, 2008. 
6 Hoch S, Thelen K, Vorwerk H, Netzer C, Wilhelm T, Gunzel T and Teymoortash A: Impact of different treatment concepts on regional failure in advanced oropharyngeal cancer. Anticancer Res 37: 727-734, 2017.

7 Boeckx C, Baay M, Wouters A, Specenier P, Vermorken JB, Peeters $\mathrm{M}$ and Lardon F: Anti-epidermal growth factor receptor therapy in head and neck squamous cell carcinoma: Focus on potential molecular mechanisms of drug resistance. Oncologist 18: 850-864, 2013.

8 Brand TM, Iida M and Wheeler DL: Molecular mechanisms of resistance to the EGFR monoclonal antibody cetuximab. Cancer Biol Ther 11: 777-792, 2011.

9 Theile D, Ketabi-Kiyanvash N, Herold-Mende C, Dyckhoff G, Efferth T, Bertholet V, Haefeli WE and Weiss J: Evaluation of drug transporters' significance for multidrug resistance in head and neck squamous cell carcinoma. Head Neck 33: 959-968, 2011.

10 Seidl D, Schild SE, Wollenberg B, Hakim SG and Rades D: Prognostic factors in patients irradiated for recurrent head-andneck cancer. Anticancer Res 36: 6547-6550, 2016.

11 Shirai K, Saitoh JI, Musha A, Abe T, Kobayashi D, Takakusagi Y, Takaysu Y, Shino M, Toyoda M, Takahashi K, Chikamatsu K, Ohno T and Nakano T: Clinical outcomes of definitive and postoperative radiotherapy for stage I-IVB hypopharyngeal cancer. Anticancer Res 36: 6571-6578, 2016.

12 Feldman R, Gatalica Z, Knezetic J, Reddy S, Nathan CA, Javadi $\mathrm{N}$ and Teknos T: Molecular profiling of head and neck squamous cell carcinoma. Head Neck 38(Suppl 1): E1625-E1638, 2016.

13 Laban S, Doescher J, Schuler PJ, Bullinger L, Brunner C, Veit JA and Hoffmann TK: Immunotherapy of head and neck tumors: Highlights of the ASCO Meeting 2015. HNO 63: 612-619, 2015

14 Jacobi C, Ayx I, Fritsche K, Piontek G, Hoffmann D, Weirich G and Knopf A: Potential impact of human papilloma virus on survival of basaloid squamous carcinoma of the head and neck Oncotarget 6: 3462-3470, 2015.

15 Fakhry C, Westra WH, Li S, Cmelak A, Ridge JA, Pinto H, Forastiere A and Gillison ML: Improved survival of patients with human papillomavirus-positive head and neck squamous cell carcinoma in a prospective clinical trial. J Natl Cancer Inst 100: 261-269, 2008.

16 Okami K: Clinical features and treatment strategy for HPVrelated oropharyngeal cancer. Int J Clin Oncol 21: 827-835, 2016.

17 Baumeister P, Rauch J, Jacobi C, Kisser U, Betz C, Becker S and Reiter M: Impact of comorbidity and anemia in patients with oropharyngeal cancer primarily treated with surgery in the human papillomavirus era. Head Neck 39(1): 7-16, 2016.

18 Sablin MP, Dubot C, Klijanienko J, Vacher S, Ouafi L, Chemlali W, Caly M, Sastre-Garau X, Lappartient E, Mariani O, Rodriguez J, Jouffroy T, Girod A, Calugaru V, Hoffmann C, Lidereau R, Berger F, Kamal M, Bieche I and Le Tourneau C: Identification of new candidate therapeutic target genes in head and neck squamous cell carcinomas. Oncotarget 7(30): 47418-47430, 2016.

19 Morris LG, Chandramohan R, West L, Zehir A, Chakravarty D, Pfister DG, Wong RJ, Lee NY, Sherman EJ, Baxi SS, Ganly I, Singh B, Shah JP, Shaha AR, Boyle JO, Patel SG, Roman BR, Barker CA, McBride SM, Chan TA, Dogan S, Hyman DM, Berger MF, Solit DB, Riaz N and Ho AL: The molecular landscape of recurrent and metastatic head and neck cancers: Insights from a precision oncology sequencing platform. JAMA Oncol, 2016. [Epub ahead of print].
20 Ledgerwood LG, Kumar D, Eterovic AK, Wick J, Chen K, Zhao H, Tazi L, Manna P, Kerley S, Joshi R, Wang L, Chiosea SI, Garnett JD, Tsue TT, Chien J, Mills GB, Grandis JR and Thomas SM: The degree of intratumor mutational heterogeneity varies by primary tumor sub-site. Oncotarget 7(19): 27185-27198, 2016.

21 Loyo M, Li RJ, Bettegowda C, Pickering CR, Frederick MJ, Myers JN and Agrawal N: Lessons learned from next-generation sequencing in head and neck cancer. Head Neck 35: 454-463, 2013.

22 Gerlinger M, Rowan AJ, Horswell S, Larkin J, Endesfelder D, Gronroos E, Martinez P, Matthews N, Stewart A, Tarpey P, Varela I, Phillimore B, Begum S, McDonald NQ, Butler A, Jones D, Raine K, Latimer C, Santos CR, Nohadani M, Eklund AC, Spencer-Dene B, Clark G, Pickering L, Stamp G, Gore M, Szallasi Z, Downward J, Futreal PA and Swanton C: Intratumor heterogeneity and branched evolution revealed by multiregion sequencing. N Engl J Med 366: 883-892, 2012.

23 Mack B, Eggert C, Eder K, Imrich S, Baumeister P, Harreus U and Gires O: Rapid and non-enzymatic in vitro retrieval of tumour cells from surgical specimens. PLoS One 8: e55540, 2013.

24 Yan M, Yang X, Wang L, Clark D, Zuo H, Ye D, Chen W and Zhang P: Plasma membrane proteomics of tumor spheres identify CD166 as a novel marker for cancer stem-like cells in head and neck squamous cell carcinoma. Mol Cell Proteomics 12: 3271-3284, 2013.

25 Yang WH, Lan HY, Tai SK and Yang MH: Repression of bone morphogenetic protein 4 by let- $7 \mathrm{i}$ attenuates mesenchymal migration of head and neck cancer cells. Biochem Biophys Res Commun 433: 24-30, 2013.

26 Chang CC, Hsu WH, Wang CC, Chou CH, Kuo MY, Lin BR, Chen ST, Tai SK, Kuo ML and Yang MH: Connective tissue growth factor activates pluripotency genes and mesenchymalepithelial transition in head and neck cancer cells. Cancer Res 73: 4147-4157, 2013.

27 Duarte S, Loubat A, Momier D, Topi M, Faneca H, Pedroso de Lima MC, Carle GF and Pierrefite-Carle V: Isolation of head and neck squamous carcinoma cancer stem-like cells in a syngeneic mouse model and analysis of hypoxia effect. Oncol Rep 28: 1057-1062, 2012.

28 Cancer Genome Atlas N: Comprehensive genomic characterization of head and neck squamous cell carcinomas. Nature 517: 576-582, 2015.

29 Weiswald LB, Bellet D and Dangles-Marie V: Spherical cancer models in tumor biology. Neoplasia 17: 1-15, 2015.

30 Lin RZ and Chang HY: Recent advances in three-dimensional multicellular spheroid culture for biomedical research. Biotechnol J 3: 1172-1184, 2008.

31 Kelm JM, Timmins NE, Brown CJ, Fussenegger M and Nielsen LK: Method for generation of homogeneous multicellular tumor spheroids applicable to a wide variety of cell types. Biotechnol Bioeng 83: 173-180, 2003.

32 Kunz-Schughart LA, Freyer JP, Hofstaedter F and Ebner R: The use of 3-D cultures for high-throughput screening: The multicellular spheroid model. J Biomol Screen 9: 273-285, 2004.

33 Ham SL, Joshi R, Thakuri PS and Tavana H: Liquid-based threedimensional tumor models for cancer research and drug discovery. Exp Biol Med (Maywood) 241(9): 939-954, 2016. 
34 Anastasov N, Hofig I, Radulovic V, Strobel S, Salomon M, Lichtenberg J, Rothenaigner I, Hadian K, Kelm JM, Thirion C and Atkinson MJ: A 3D-microtissue-based phenotypic screening of radiation resistant tumor cells with synchronized chemotherapeutic treatment. BMC Cancer 15: 466, 2015.

35 Vinci M, Gowan S, Boxall F, Patterson L, Zimmermann M, Court W, Lomas C, Mendiola M, Hardisson D and Eccles SA: Advances in establishment and analysis of three-dimensional tumor spheroid-based functional assays for target validation and drug evaluation. BMC Biol 10: 29, 2012.

36 Zhang S, Balch C, Chan MW, Lai HC, Matei D, Schilder JM, Yan PS, Huang TH and Nephew KP: Identification and characterization of ovarian cancer-initiating cells from primary human tumors. Cancer Res 68: 4311-4320, 2008.

37 Friedrich J, Seidel C, Ebner R and Kunz-Schughart LA: Spheroid-based drug screen: considerations and practical approach. Nat Protoc 4: 309-324, 2009.

38 Borrell B: How accurate are cancer cell lines? Nature 463: 858, 2010.

39 Wilding JL and Bodmer WF: Cancer cell lines for drug discovery and development. Cancer Res 74: 2377-2384, 2014.

40 van der Worp HB, Howells DW, Sena ES, Porritt MJ, Rewell S, O'Collins V and Macleod MR: Can animal models of disease reliably inform human studies? PLoS Med 7: e1000245, 2010.

41 Bobbs AS, Cole JM and Cowden Dahl KD: Emerging and evolving ovarian cancer animal models. Cancer Growth Metastasis 8: 29-36, 2015.

42 Sharafinski ME, Ferris RL, Ferrone $\mathrm{S}$ and Grandis JR: Epidermal growth factor receptor targeted therapy of squamous cell carcinoma of the head and neck. Head Neck 32: 1412-1421, 2010.

43 Price KA and Cohen EE: Mechanisms of and therapeutic approaches for overcoming resistance to epidermal growth factor receptor (EGFR)-targeted therapy in squamous cell carcinoma of the head and neck (SCCHN). Oral Oncol 51: 399-408, 2015.

44 Bauml JM, Cohen RB and Aggarwal C: Immunotherapy for head and neck cancer: Latest developments and clinical potential. Ther Adv Med Oncol 8: 168-175, 2016.

45 Nath S and Devi GR: Three-dimensional culture systems in cancer research: Focus on tumor spheroid model. Pharmacol Ther 163: 94-108, 2016.

46 Sutherland RM: Cell and environment interactions in tumor microregions: The multicell spheroid model. Science 240: 177184, 1988.

47 Santini MT and Rainaldi G: Three-dimensional spheroid model in tumor biology. Pathobiology 67: 148-157, 1999.

48 Thoma CR, Zimmermann M, Agarkova I, Kelm JM and Krek $\mathrm{W}$ : 3D cell culture systems modeling tumor growth determinants in cancer target discovery. Adv Drug Deliv Rev 69-70: 29-41, 2014.

49 Tupper J GO, Tozer GM, Dachs GU: Analysis of the horseradish peroxidase/indole-3-acetic acid combination in a threedimensional tumor model. Cancer Gene Ther 11: 508-513, 2004.

50 Hsu YF, Ajona D, Corrales L, Lopez-Picazo JM, Gurpide A, Montuenga LM and Pio R: Complement activation mediates cetuximab inhibition of non-small cell lung cancer tumor growth in vivo. Mol Cancer 9: 139, 2010.

51 Pickl M and Ries CH: Comparison of 3D and 2D tumor models reveals enhanced HER2 activation in 3D associated with an increased response to trastuzumab. Oncogene 28: 461-468, 2009.
52 Kadletz L, Heiduschka G, Domayer J, Schmid R, Enzenhofer E and Thurnher D: Evaluation of spheroid head and neck squamous cell carcinoma cell models in comparison to monolayer cultures. Oncol Lett 10: 1281-1286, 2015.

53 Ingargiola M, Runge R, Heldt JM, Freudenberg R, Steinbach J, Cordes N, Baumann M, Kotzerke J, Brockhoff G and KunzSchughart LA: Potential of a cetuximab-based radioimmunotherapy combined with external irradiation manifests in a 3-D cell assay. Int J Cancer 135: 968-980, 2014.

54 Friedrich J, Ebner R and Kunz-Schughart LA: Experimental anti-tumor therapy in 3-D: Spheroids - old hat or new challenge? Int J Radiat Biol 83: 849-871, 2007.

55 McMillin DW, Negri JM and Mitsiades CS: The role of tumourstromal interactions in modifying drug response: challenges and opportunities. Nat Rev Drug Discov 12: 217-228, 2013.

56 Tibbitt MW and Anseth KS: Dynamic microenvironments: the fourth dimension. Sci Transl Med 4: 160ps124, 2012.

$57 \mathrm{Kim}$ SH, Turnbull J and Guimond S: Extracellular matrix and cell signalling: The dynamic cooperation of integrin, proteoglycan and growth factor receptor. J Endocrinol 209: 139$151,2011$.

58 Longati P, Jia X, Eimer J, Wagman A, Witt MR, Rehnmark S, Verbeke C, Toftgard R, Lohr M and Heuchel RL: 3D pancreatic carcinoma spheroids induce a matrix-rich, chemoresistant phenotype offering a better model for drug testing. BMC Cancer 13: 95, 2013.

59 Aggarwal BB, Danda D, Gupta S and Gehlot P: Models for prevention and treatment of cancer: Problems vs. promises. Biochem Pharmacol 78: 1083-1094, 2009.

60 Chitcholtan K, Asselin E, Parent S, Sykes PH and Evans JJ: Differences in growth properties of endometrial cancer in three dimensional (3D) culture and 2D cell monolayer. Exp Cell Res 319: 75-87, 2013.

61 Perche F and Torchilin VP: Cancer cell spheroids as a model to evaluate chemotherapy protocols. Cancer Biol Ther 13: 12051213, 2012.

62 Olive PL and Durand RE: Drug and radiation resistance in spheroids: cell contact and kinetics. Cancer Metastasis Rev 13: 121-138, 1994.

63 Laurent J, Frongia C, Cazales M, Mondesert O, Ducommun B and Lobjois V: Multicellular tumor spheroid models to explore cell cycle checkpoints in 3D. BMC Cancer 13: 73, 2013.

64 Barbone D, Yang TM, Morgan JR, Gaudino G and Broaddus VC: Mammalian target of rapamycin contributes to the acquired apoptotic resistance of human mesothelioma multicellular spheroids. J Biol Chem 283: 13021-13030, 2008.

65 Dubessy C, Merlin JM, Marchal C and Guillemin F: Spheroids in radiobiology and photodynamic therapy. Crit Rev Oncol Hematol 36: 179-192, 2000.

66 Durand RE and Sutherland RM: Effects of intercellular contact on repair of radiation damage. Exp Cell Res 71: 75-80, 1972. 